\section{Quantification of periodontal attachment at single-rooted teeth}

\author{
Hujoel P, Bollen A-M and Schork A: Quantification of periodontal attachment at \\ single-rooted teeth. J Clin Periodontol 1989; 16: 224-228.
}

\begin{abstract}
The measurement process of attachment loss has been criticized in recent years. Problems with clinical interpretation, precision of the measurement, and statistical manipulation of the obtained data, are some of the problems associated with the present methodology. The purpose of the present study was to propose an alternative measurement process which addresses some of the existing problems by estimating the lost attachment surface area (LAS) and the remaining attachment surface area (RAS) from a combination of clinical measurements. The results show that a linear combination of several sources of clinical information can be used to predict RAS and LAS. A diagnostic model for LAS $\left(R^{2}=81.5 \%\right)$ predicts the square root of LAS with information obtained from bucco-lingual attachment level measurements, the radiographic lost attachment area, the gingivitis index and the radiographic tooth length. This model increases the precision of the estimate of LAS by a factor of 1.86 when compared to the estimate of LAS using only attachment level measurements. A diagnostic model for RAS $\left(R^{2}=75.5 \%\right)$ predicts the square root of RAS with the information obtained from the remaining radiographic attachment area, the gingivitis index and the mobility index. Both linear inference models are constructed with measurements of anatomical landmarks to avoid the discrepancy between anatomical and clinical measurements in the produced estimates. It is concluded that modeling of periodontal data provides a simple, inexpensive, and precise diagnostic tool for predicting the lost and the remaining periodontal attachment of single-rooted teeth. Measurement processes of this type could provide a convincing basis for the evaluation of clinical decisions and research questions.
\end{abstract}

P. Hujoel' ${ }^{1}$, A.-M. Bollen ${ }^{2}$ and A. Schork ${ }^{1}$

'Department of Biostatistics, ${ }^{2}$ Dental Research Institute, University of Michigan, Ann Arbor, MI 48104, USA
Key words: lost attachment surface area; remaining attachment surface area; linear models; prediction; diagnostic models.

Accepted for publication 9 May 1988
The clinical assessment of the periodontal attachment status commonly utilizes information obtained from probing depth measurements, a radiographic examination and an evaluation of the inflammatory status of the tissues. The totality of this information can be integrated by the clinician in order to estimate the degree of periodontal destruction and the amount of remaining support. This mental integration process has not been quantified and this has created problems with the interpretation of linear measurements obtained from probings and/or radiographs.

A first problem associated with linear measurements obtained from a radiograph or a probe is the discrepancy between the clinical measurement and the anatomical measurement (Listgarten 1980). For instance, the periodontal probe can over or under-estimate the apical termination of the junctional epithelium according to the gingival index of the tissues (Magnusson \& Listgarten
1980). Similarly, bone destruction may be overestimated due to acute inflammation or underestimated due to lack of information of the bone level on the buccal and lingual side of the tooth (Theilade 1960). A second problem results because linear measurements attempt to estimate two-dimensional information with one-dimensional measurements. For instance, a linear measurement of a vertical defect does not carry any information with regard to the width of the defect. Also, a similar amount of linear disease progression in the coronal third versus the apical third may entail large differences in actual connective tissue loss due to root tapering. Therefore, if the purpose of periodontal disease assessment is to estimate the 'true' periodontal attachment loss, vertical linear measurements may represent a poor estimate. A third problem is the insufficient use of available clinical information. Although a clinical exam commonly consists of the collec- tion of observations on several variables, usually only attachment level measurements will be reported. However, a combination of for instance radiographic information and attachment level measurements, as opposed to the exclusive use of attachment level measurements, could lead to a more accurate estimate of the connective tissue attachment loss.

Although the clinician constantly evaluates the above factors in his/her assessment of the periodontal status, communication among clinicians and clinical research is hampered by the absence of a model which integrates the available clinical information to estimate the periodontal status of the teeth. The purpose of this study is to build statistical models, based on clinical measurements, which will quantify the lost and the remaining periodontal attachment of single-rooted teeth. To illustrate how the linear model works in a clinical setting, several applications with 
regard to a particular patient of this sample are presented.

\section{Material and Methods}

Patients presenting to the Department of Oral Surgery at the University of Michigan for tooth extraction were screened between June and December of 1987. The decision to extract a tooth was made by clinicians not involved in the study, and informed consent was obtained from all participants in accordance with the guidelines established by the University of Michigan for the protection of human subjects. Patients were selected on the following criteria: (1) a radiograph not older than 20 days for the tooth to be extracted, (2) no extensive root caries and/or gross destruction of the cemento-enamel-junction, (3) the presence of a clinical crown, and (4) a projected simple extraction procedure. If fracturing occurred during the extraction the tooth was discarded.

During this ongoing study, there were 38 patients with a total of 64 singlerooted teeth extractions. In order to observe the independence of the observations only one tooth per patient was included in the study. The mean age of this patient group was 49 years. Of the teeth extracted, $27 \%$ were extracted due to caries, $43.2 \%$ were extracted for periodontal reasons, $5.4 \%$ were extracted for orthodontic reasons and $18.9 \%$ was extracted for other reasons. This group included patients whose teeth were extracted for restorative, occlusal, or other reasons. The selected sample of 38 teeth included 1 single-rooted molar, 21 premolars, 10 incisors and 5 cuspids.

Prior to extraction the pocket depth was measured as the distance from the base of the sulcus to the crest of the free gingival margin and the attachment level was measured from the base of the sulcus to the cemento-enamel junction. All measurements were taken by the same operator at the line-angles of the teeth. Other variables such as gingival index, tooth mobility, age, and sex, were included. The information that was quantified on the radiograph is shown in Fig. 1. The radiographic measurements were standardized with the Bioquant software program based on the tooth width which was measured with a caliper. All clinical measurements used as predictor variables are summarized in Table 1, including the data obtained for a particular patient from this

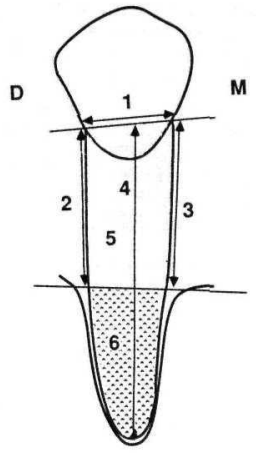

Fig. 1. Clinical variables obtained from the radiograph are (1) tooth width, (2) distal bone loss, (3) mesial bone loss, (4) tooth length (RTL), (5) lost attachment surface area (RLA), and (6) remaining attachment surface area (RRA).

sample. Several variables were transformed into new variables: the gingivitis index and the mobility score were both transformed into indicator variables with a GI index or mobility score smaller than 2 set equal to 0 and a GI index or a mobility score larger than 1 set equal to 1. Also, the attachment level measurements were summarized into a bucco-lingual summary value (BLA), which equaled the lingual + buccal attachment level, and, a total summary value (TLA), which equaled the sum of all 6 observations around a tooth. Similar transformations were done for pocket depth measurements.

Following extraction each tooth was fixed in formaldehyde and the perio- dontal attachment was stained with a concentrated acetic acid solution of alcian blue $(\mathrm{pH} \mathrm{2.0)}$. After rinsing and removal of the plaque with a soft toothbrush the tooth was dried. Nylon thread, $0.12 \mathrm{~mm}$ in diameter, was fixed on the line-angles of the tooth with cyanoacrylate. Macroscopic Kodachrome slides were taken of the surfaces defined by the wire. The slides were projected on a HIPAD digitizing tablet and the lost attachment surface area (LAS), the remaining attachment surface area (RAS), and the total attachment surface area (TAS) were quantified in square $\mathrm{mm}$ with the Bioquant Image Analysis System $^{*}$.

All collected data were analyzed using univariate multiple regression models with RAS and LAS as response variables and the clinical measurements collected prior to extraction as predictor variables. Transformations of the response variables were explored with normal probability plots of the residuals. The determination of a good subset of clinical predictor variables was addressed utilizing the stepwise regression technique, determination of the optimal subset, and subjective judgment (Hocking 1976). The stopping rule for the stepwise regression was a partial $F$, significant with $P<0.15$. The evaluation of the model included other criteria such as the $R^{2}$-criterion, Mallow's $C_{\mathrm{p}}$-plots, JP and SP. The appropriateness of the final selected linear models was assessed for collinearity and by the use of influence diagnostics. A variance inflation factor (VIF) in excess of 10 was taken as an indication of multicollinearity. The outlier cutoffs for the residuals were \pm 2.7 standard deviations. The precision of the diagnostic models was defined as the inverse of the variance of the linear model.
Table 1. 11 variables used in building the linear regression model

\begin{tabular}{lc}
\hline Clinical predictor variables & Patient example \\
\hline total attachment loss (TLA) & $43 \mathrm{~mm}$ \\
total probing depth (TPD) & $42 \mathrm{~mm}$ \\
modified gingivitis index (MGI) & 1 \\
modified mobility index (MOB) & 1 \\
radiographic remaining attachment area (RRA) & $6.9 \mathrm{~mm}^{2}$ \\
radiographic lost attachment area (RLA) & $28 \mathrm{~mm}^{2}$ \\
mean radiographic interproximal bone loss (MRI) & $10 \mathrm{~mm}$ \\
bucco-lingual attachment loss (BLA) & $11 \mathrm{~mm}$ \\
radiographic tooth length (RTL) & $13.7 \mathrm{~mm}$ \\
lost attachment surface area (LAS) & $113.8 \mathrm{~mm}^{2}$ \\
remaining attachment surface area (RAS) & $34.8 \mathrm{~mm}^{2}$ \\
\hline
\end{tabular}




\section{Results}

Lost attachment surface area (LAS)

Statistical aspects of the model. Exploratory data analysis indicated that a square root transformation of the response variable resulted in a reasonably linear relation. Residual plots for the fitted regression models showed no graphical evidence of a lack of fit and no strong evidence of unequal error variances. Tests for collinearity indicated that lost radiographic attachment area and mean radiographic interproximal bone loss were highly multicollinear $(\mathrm{VIF}=13)$ and should therefore not be included simultaneously in the model. An evaluation of the influence diagnostics indicated that no outliers or significantly influential observations were present. A stepwise regression search indicated the subset of 4 predictor variables. This selected subset was also identified as the optimum subset of size 4 to predict the lost attachment area and agreed to a certain extent with clinical intuition. The $R^{2}$ of this model was $81.5 \%$, which indicates that $81.5 \%$ of the total variation in the lost attachment surface area (LAS) was explained with the use of the 4 predictor variables.

Applied aspects of the model. Clinical and statistical evidence indicated that 4 out of the 9 predictor variables shown in Table 1 are 'good' predictors for LAS: (1) the lost radiographic attachment area, (2) the gingival index, (3) the bucco-lingual attachment loss, and (4) the radiographic tooth length. The fitted regression equation was:

$\sqrt{\text { Lost attachment area }}=6.71+0.12$
$\times$ (bucco-lingual attachment loss $)$
$+0.13 \times($ radiographic lost attach-
ment area $)$
$+3.56 \times($ modified gingival index $)$
$-0.33 \times$ (radiographic tooth length)

This model enables us to predict the lost attachment surface area based on clinical measurements. For instance, for a particular patient of this sample, we can now calculate an estimate of the lost periodontal attachment by inserting the indicated clinical measurements in the regression equation (1). The result is

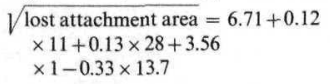

which is equal to 10.7 . We conclude that the estimate of the attachment loss is $115 \mathrm{~mm}^{2}$ (observing that the square root

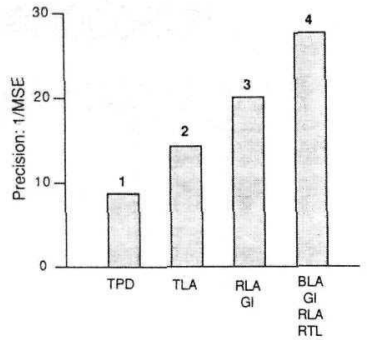

Fig. 2. Efficiency of 5 different models in the prediction of attachment loss. (1) Model with total pocket depth as predictor variable, (2) model with total attachment level as predictor variable, (3) model with radiographic lost attachment and gingivitis index as predictor variables and (4) the final selected model with bucco-lingual attachment loss, radiographic lost attachment surface area, gingivitis index and radiographic tooth length as predictor variables. Note the steady increase in precision as more clinical information is used to predict LAS.

of the response was taken, we now need to square 10.7 ). With a confidence coefficient of $95 \%$, we estimate that the lost periodontal attachment of the subject would be somewhere between $94 \mathrm{~mm}^{2}$ and $134 \mathrm{~mm}^{2}$

The precisions of 4 different diagnostic models are shown in Fig. 2. From this figure we can see that the combination of clinical measurements significantly increases the precision of estimates. The model specified in equation (1) produces estimates which are 1.87 times more precise as the estimates produced with the use of attachment level measurements alone and 3.3 times more accurate than the estimates produced with use of probing depth measurements.

\section{Remaining attachment surface area (RAS)}

Statistical aspects of the model. The square root transformation enhanced the normality and equal variance assumption. One single rooted maxillary molar was marginally considered as an outlier with a studentized residual of -2.8 . However this tooth was not rejected. A stepwise regression search indicated that the modified gingivitis index, the modified mobility index, the radiographic remaining attachment, and the total pocket depth, were a 'good' subset to predict the remaining attachment surface. Although this subset was also the optimum subset, we opted to delete the predictor variable total pocket depth in the final model. Although this variable may have been a good predictor variable for this particular sample, we judged that this may not be true for other samples. The $R^{2}$ of this model was $75.5 \%$.

Applied aspects of the model. Clinical judgment was an important in the selection of an appropriate model since only one of the 9 predictor variables was directly related with the amount of remaining attachment. The fitted regression equation for RAS was:

$$
\begin{aligned}
& \sqrt{\text { remaining attachment surface area }} \\
& =8.45+0.11 \times \text { (remaining radio- } \\
& \text { graphic attachment area) } \\
& -0.77 \times \text { (modified gingivitis index) } \\
& -2.46 \times \text { (modified mobility index) }
\end{aligned}
$$

The remaining periodontal attachment for the particular patient of this sample patient as estimated from the fitted regression equation (2) is:

$\sqrt{\text { remaining attachment surface }}=8.45$ $+0.11 \times 6.9-0.77 \times 1-2.46 \times 1$ or 6 . Thus we estimate that the remaining periodontal attachment is $36 \mathrm{~mm}^{2}\left(6^{2}\right)$ and with a confidence coefficient of $95 \%$, we estimate that the remaining periodontal attachment for this patient would be somewhere between $22 \mathrm{~mm}^{2}$ and 53 $\mathrm{mm}^{2}$.

\section{Discussion}

The question whether the model obtained is a good one is best addressed by two principles discussed by McCullagh \& Nelder (1983). A first principle is that all models are wrong. However, some are better than others and we can search for the better ones. At the same time we must realize that the exact assessment of the lost or the remaining surface attachment area is not within our grasp. A systematic error of the presented model is the underestimation of the true periodontal attachment due to ignoring slight surface curvatures of the teeth. The magnitude of this error was minimized by dividing the tooth surface in approximately flat planes. It is presently difficult to digitize three-dimensional surfaces with chromatographic distinctions. (Three dimensional reconstructions are possible from histological sections, this method however is very tedious and hardly feasible for large 
samples.) A subjective part of the model was the deletion of pocket depth for the estimation of RAS. Since pocket depth was not a good predictor variable for LAS, we concluded it could not contain information for RAS.

The second principle is not to use one model to the exclusion of others. From the data gathered it was obvious that several models can be utilized to predict the attachment status. Many factors such as economics, availability of particular types of data from past research, purpose of the study, sample size, etc., will play a role in the decision of choosing the most appropriate model. These linear models should not be considered as final models, but rather as bases for further development as more information becomes available.

The proposed models have the advantage of being a simple, flexible, and precise tools for estimating the periodontal status of a single-rooted tooth. Some multiplications and additions, feasible on a pocket calculator, are sufficient to estimate the periodontal attachment status of a tooth. The methods are flexible since the diagnostic models can easily be modified to the type of data available in a particular situation. For instance, if the variable lost radiographic attachment area is not obtainable, it can be replaced by MRI with only a slight loss in precision. Thus, with the collection of 3 easily obtainable clinical measurements, one can obtain a precise estimate of the periodontal status of a single-rooted tooth. Although we have shown that the model is 1.87 times as precise as using attachment level measurements alone, this modeling does not take away the need for more precise diagnostic techniques. New techniques should be investigated to assess how much "additional" information over a clinical and radiographical examination they bring to the clinician. In statistical terms, the question for new diagnostic tools revolves around how well they improve the precision of the predictions.

Measurement processes of this type provide a basis for the evaluation of clinial decisions and research questions. Several aspects of models of this type support their face validity (the validity based on intuitive grounds): (1) attachment loss is quantified as the root surface area of connective tissue lost, and not as linear measurement which may not be representative of the actual connective tissue loss incurred, (2) the vari- ables quantified are closely related to clinical decision making processes and (3) inference is made to the anatomical periodontal attachment and thereby avoids the discrepancy of clinical versus anatomical measurements. The construct validity (validity based on substantive theoretical grounds) of the model is supported by the theory of linear models which is used in other medical diagnostic fields.

We conclude that statistical models of this type would be useful as a diagnostic adjunct and that they provide a convincing basis for the evaluation of the periodontal status of single-rooted teeth. The flexibility, precision and inexpensive nature of the models allow application in a variety of situations. In subsequent papers the models will be generalized to predictions for multirooted teeth and for the total attachment status of patients.

\section{Zusammenfassung}

Die Quantifizierung des parodontalen Attachments bei einwurzeligen Zähnen

In den letzten Jahren wurde die Methode zur Messung des parodontalen Attachmentverlustes kritisiert. Einige der Probleme der z.Zt. angewendeten Methode sind: die klinische Interpretation, die Messungsgenauigkeit und die statistische Bearbeitung der Daten. Die hier vorliegende Untersuchung wurde konzipiert, um ein alternatives Vorgehen bei der Messung vorzuschlagen, das mit Hilfe einer Kombination klinischer Messresultate auf einige der vorhandenen Probleme Bezug nimmt, und zwar durch die Schätzung der "Lost Attachment Surface $=$ Verlorenen Attachmentoberfläche (LAS)" und der "Remaining Attachment Surface $=$ Verbliebenen Attachmentoberfläche (RAS)". Ein diagnostisches Modell für LAS $\left(R^{2}=81.5 \%\right)$ sagt die Quadratwurzel der LAS mittels Informationen voraus, die sich aus Messungen bukko-lingualer Attachmentniveaus der röntgenographisch verlorenen Attachmentfläche, dem Gingivalindex und der röntgenographisch ermittelten Länge des Zahnes zusammensetzen. Dieses Modell erhöht, im Vergleich mit dem Schätzwert des LAS der nur von Attachmentniveaumessungen stammt, die Genauigkeit der Schätzung um den Fak- tor 1.86. Ein diagnostisches Modell für die RAS $\left(R^{2}=75.5 \%\right)$ sagt die Quadratwurzel der RAS mit Hilfe der Informationen voraus, die von dem röntgenologisch ermittelten, verbliebenen Attachment, dem Gingivitis-Index und dem Zahnlockerungs-Index stammt. Beide Linearmodelle gehen von anatomischen Bezugspunkten aus, um bei den ermittelten Schätzwerten Schwierigkeiten durch Diskrepanzen zwischen anatomischen und klinischen Messungen zu umgehen. Es wird gefolgert, dass das "Modellieren" parodontaler Messwerte ein einfaches, kostengünstiges und genaues diagnostisches Hilfsmittel zur Voraussage des verlorenen und verbliebenen parodontalen Attachments bei einwurzeligen Zähnen ist. Derartige Messmethoden können für eine sichere Basis klinischer Entscheidungen, wie auch für wissenschaftliche Fragen von Nutzen sein.

\section{Résumé}

Evaluation quantitative de l'attache parodontale sur les monoradiculees

Le procédé utilisé pour mesurer la perte d'attache parodontale a fait l'objet de critiques ces dernières années. Quelques-uns des problèmes que pose la méthode actuelle concernent l'interprétation clinique, la précision des mesures et le traitement statistique des données obtenues. Le but de la présente étude est de proposer un autre procédé visant à résoudre quelques-uns des problèmes existants en se basant sur une combinaison de mesures cliniques pour estimer la superficie de la perte d'attache (LAS) et la superficie de l'attache restante (RAS). Les résultats montrent qu'on peut utiliser une combinaison linéaire d'informations cliniques de différentes origines pour prédire LAS et RAS. Un modèle diagnostique de LAS $\left(R^{2}=81.5 \%\right)$ prédit la racine carrée de LAS à partir d'informations données par les mesures vestibulo-linguales du niveau de l'attache, la surface de la perte d'attache radiographique, l'Indice de Gingivite et la longueur radiographique de la dent. Ce modele multiplie par 1.86 la précision des évaluations de LAS par comparaison avec l'évaluation de LAS basée uniquement sur les mesures du niveau de l'attache. Pour RAS, un modèle diagnostique $\left(R^{2}=75.5 \%\right)$ prédit la racine carrée de RAS à partir des informations données par le reste radiographique de l'attache (RRA), l'Indice de Gingivite et l'Indice de Mobilité. Ces deux modèles d'inférence linéaire sont construits à partir de points de repère anatomiques pour

\section{References}

Hocking, R. R. (1976) The analysis and selection of variables in linear regression. Biometrics 32, 1-49.

Listgarten, M. A. (1980) Periodontal probing: what does it mean? Journal of Clinical Periodontology 7, 165-176.

Magnusson, 1. \& Listgarten, M. A. (1980) Histological evaluation of probing depth following periodontal treatment. Journal of Clinical Periodontology 7, 26-31. 
éviter, dans l'évaluation en résultant, les divergences entre les mesures anatomiques et les mesures cliniques. En conclusion, l'emploi d'un modèle des données parodontales constitue un outil diagnostique simple et précis pour prédire l'étendue de la perte d'attache et du reste d'attache parodontale sur des monoradiculées. Ce type de méthode de mesure pourrait offrir une base solide pour l'évaluation des décisions cliniques et des problèmes de recherche.
McCullagh, P. \& Nelder, J. A. (1983) Generalized linear models. Monographs on Statistics and applied probability, p. 6. London: Chapman and Hall.

Theilade, J. (1960) An evaluation of the reliability of radiographs in the measurement of bone loss in periodontal disease. Journal of Periodontology 31, 143-153.

Address:

Philippe Hujoel

1344 McIntyre Drive

Ann Arbor, MI 48104

USA 
This document is a scanned copy of a printed document. No warranty is given about the accuracy of the copy. Users should refer to the original published version of the material. 